\title{
A UTILIZAÇÃO DAS OBRAS INTELECTUAIS AUTORAIS FRENTE ÀS NOVAS TECNOLOGIAS: FUNÇÃO SOCIAL OU PIRATARIA?
}

\author{
Eduardo Pires ${ }^{1}$ \\ Jorge Renato dos Reis ${ }^{2}$
}

\begin{abstract}
RESUMO
Modernamente verifica-se a existência de um novo modelo de sociedade denominada de Sociedade da Informação, decorrente, sobretudo, do surgimento de novas tecnologias de comunicação que facilitam o acesso à informação e também às obras intelectuais. Nesse novo contexto, evidencia-se ainda mais o histórico conflito existente entre sociedade e autor, especificamente no que concerne ao direito de acesso à informação pleiteado pela sociedade e o direito do autor à remuneração pela utilização dos bens intelectuais frutos de sua criação. Da análise do referido conflito, sobretudo, considerando o caráter restritivo da lei 9.610/98 e das limitações ao direito do autor, percebe-se que a atual lei de direitos autorais torna-se incompatível com as atuais práticas sociais possibilitadas pelas novas tecnologias, muito especialmente, pela Internet, servindo de obstáculo para a efetivação dos direitos fundamentais à informação, educação e cultura. Sendo assim, a sociedade como um todo, vem corriqueiramente infringindo os direitos autorais, seja, por exemplo, quando se faz o download de um filme para o computador para uso particular, seja quando se copia uma música para o IPOD mesmo que de um CD comprado, seja quando se tira cópia de um livro para uso educacional, mesmo que a obra esteja esgotada, entre muitos outro exemplos. No entanto, este tipo de utilização referido, que seja para uso privado e sem fins lucrativos não pode ser taxado de Pirataria e muito menos considerado como crime, pois considerando que o direito de autor, assim como os demais institutos de direito privado, deve cumprir uma função social. Pode-se, portanto, afirmar que estas formas de utilização dos bens intelectuais, sem intuito de lucro, encontram-se, justamente, dentro do âmbito do que entende por função social do direito de autor, haja vista a incidência, nesses casos, dos direitos fundamentais a informação, cultura e educação.
\end{abstract}

Palavras-chave: Direito do autor. Função social. Novas tecnologias. Pirataria. 


\section{INTRODUÇÃO}

Os debates envolvendo direitos autorais têm se tornado comuns. Impulsionados pelo Ministério da Cultura, estão no centro das atenções, seja no âmbito acadêmico quanto no âmbito da sociedade.

O tema que sempre foi polêmico, especialmente por envolver conflitos entre interesses individuais e coletivos, torna-se ainda mais controverso a partir do surgimento e evolução das novas tecnologias, sobretudo da Internet e do consequente advento da Sociedade da Informação que tem seu fundamento baseado no conhecimento, na pesquisa, na fácil acessibilidade, compartilhamento e utilização da informação.

Nessa perspectiva, vislumbra-se que os meios tecnológicos por um lado contribuem com o desenvolvimento social na medida em que permitem à coletividade maior facilidade no acesso e disseminação do conhecimento e da cultura. Por outro lado, a fácil acessibilidade e compartilhamento dos bens intelectuais causam uma "crise" no Direito de Autor, ocasionando por conseqüência uma agudização nos conflitos entre autor e a coletividade, no que tange ao direito de retribuição pelo uso dos bens de criação do autor contra o direito de acesso a tais obras intelectuais por parte da sociedade.

Frente a este cenário, cumpre verificar se a legislação que tutela os direitos de autor encontra-se compatível com a nova realidade social e tecnológica, bem como, em consonância com os direitos fundamentais em jogo e também como devem ser caracterizadas as utilizações que ultrapassam os limites permitidos pela atual lei de direitos autorais para utilização dos bens intelectuais.

A partir disto, o que se pretende inicialmente com o presente trabalho é verificar como se dá a relação entre as novas tecnologias e o Direito Autoral, especialmente no que se refere às limitações ao Direito de Autor, com o intuito de verificar se tais dispositivos mostram-se adequados à realidade tecnológica.

Por fim, mediante a análise do que se tem chamado de Pirataria, bem como do que se entende por função social do direito de autor, deseja-se verificar dentro quais desses conceitos caracteriza a utilização das obras intelectuais fora do âmbito permitido pelas limitações dispostas na Lei 9.610/98, frente ao presente contexto social e tecnológico, bem como, considerando os direitos fundamentais em jogo.

\section{A PROTEÇÃO E AS LIMITAÇÕES AO DIREITO DE AUTOR FRENTE À INTERNET E Ả SOCIEDADE DA INFORMAÇÃO}

Presenciamos contemporaneamente uma evolução constante e veloz dos meios tecnológicos. Novos equipamentos e avanços nos meios de telecomunicação e informáticos ocasionaram uma revolução nos meios 
comunicativos e de acesso às fontes de conhecimento e cultura, o que, consequentemente, provocou o surgimento de um novo modelo de sociedade:

A emergência, desenvolvimento e difusão de novas tecnologias de informação e comunicação estariam na base da estruturação desse novo quadro de relações sociais e econômicas, configurando esse novo tipo de sociedade. $^{3}$

Tal tipo de sociedade convencionou-se chamar de "Sociedade da Informação", em que a informação e o conhecimento passam a constituir bens de imensurável valor, indispensáveis para o desenvolvimento econômico, tecnológico e cultural da sociedade.

Ocorre então, que a partir desta exigência social pelo acesso à informação aliada às inúmeras inovações tecnológicas, desponta uma alteração radical nas tradicionais práticas profissionais e sociais referentes à criação e uso dos bens intelectuais, bem como da difusão da informação e do conhecimento.

A partir da possibilidade de digitalização da informação permite-se à sociedade transpor fronteiras de conhecimento e informação nunca pensadas. "A informação em meio digital pode ser reproduzida instantaneamente, com perfeita exatidão, sem esforço significativo" ${ }^{4}$ e de forma barata, quando não gratuita.

Neste contexto, a socialização do conhecimento passa a constituir uma dos principais bases da inovação e da construção de outros novos conhecimentos. Por isso, sob o ponto de vista social, tornam-se extremamente valiosas as ferramentas que a internet e demais inovações tecnológicas proporcionam para o compartilhamento dos bens intelectuais, já que estes se constituem como fontes de conhecimento e o acesso a eles é requisito para a promoção do desenvolvimento cultural, econômico e tecnológico de uma sociedade.

Com efeito, a internet diminuiu de forma fantástica as barreiras de espaço e tempo, promovendo o desenvolvimento da Sociedade Informacional que tem seu fundamento baseado no conhecimento, na pesquisa, na fácil acessibilidade e utilização da informação. ${ }^{5}$

Contudo, este progresso tecnológico, tendo em vista permitir uma maior acessibilidade e rapidez aos bens intelectuais, provoca, nas palavras de Gonzaga Adolfo, "um tsunami no Direito Autoral"6.

Evidencia-se assim, uma conflituosidade sem proporções e de difícil solução, em que de um lado tem-se o autor, que requer a tutela sobre as suas criações, para que possa receber a remuneração pela utilização dos bens provenientes de seu intelecto, inclusive como meio de incentivo à criação; de outro lado tem-se a coletividade que pretende continuar a se beneficiar das tecnologias ora existentes para fins de acesso e difusão da informação e do conhecimento, como meio de promoção do desenvolvimento da sociedade. 
Diretamente derivado dos direitos individuais, como resultado das discussões ocorridas em decorrência dos movimentos humanistas do século XVIII e da Revolução Francesa, o Direito de Autor, tem suas raízes reconhecidas nos privilégios editoriais da Inglaterra, tendo como primeiro ato legal o Copyright Act, de 1709. Pertencente ao âmbito do Direito Privado, busca a regulação das relações jurídicas decorrentes das manifestações pessoais de criatividade e dons artísticos humanos, que podem ser economicamente utilizados. ${ }^{7}$

Em nível constitucional, a proteção ao o direito de autor encontra-se presente no inciso XIV, do artigo $5^{\circ}$ da Constituição Federal, quando prevê que ao autor é concedido o "direito exclusivo de utilização, publicação ou reprodução de suas obras" ${ }^{\prime \prime}$, conferindo-Ihe ainda o direito de fiscalização sobre a utilização econômica das obras que criar ou em que participar da criação. ${ }^{9}$ Assim, a Constituição Federal de 1988 reconhece ao Direito do Autor o status de Direito Fundamental Individual.

Infra-constitucionalmente, os direitos autorais no Brasil são regulados pela Lei 9.610 de 1998, que veio a substituir a Lei 5.988 de 1973. Esta legislação tem como objeto a proteção dos bens intelectuais de cunho literário, científico ou artístico.

Trata-se de um Direito Especial, sui generis, pois da análise do conteúdo do Direito de Autor, observa-se a coexistência de dois direitos autônomos, sendo estes os de cunho moral, relacionados à proteção da personalidade do criador da obra e outros de cunho patrimonial, referindo-se aos direitos de utilização econômica da obra. ${ }^{10}$

Todavia, a fundamentalidade e a proteção legal reconhecida ao Direito de Autor não representa que este direito seja absoluto, muito pelo contrário, pois assim como outros institutos de direito privado, como a propriedade, o contrato e a empresa, o Direito de Autor também deve cumprir uma função social. Isso significa dizer que a proteção do Direito de Autor deve estar em harmonia com os interesses sociais.

Neste sentido, Hames refere que "juntamente com a aceitação do Direito de Autor, desenvolveu-se o reconhecimento de que o mesmo está sujeito igualmente a uma vinculação social. Em nome do interesse comum, o autor deve tolerar restrições aos seus direitos". ${ }^{11}$

Algumas formas de utilização das obras intelectuais não entram no âmbito da proteção dos direitos de autor; ou seja, são de uso livre, independente de autorização ou retribuição pecuniária ao autor, o que representa o interesse público, na proteção do Direito de Autor. Tais possibilidades encontram-se dispostas no artigo 46 da LDA.

Entretanto, a Lei 9.610 de 1998, no referido artigo 46, enumera de forma taxativa estas limitações e exceções aos Direitos Autorais, quando o mais adequado do ponto de vista da função social do direito de autor seria que 
houvesse um rol aberto de limitações, regido por princípios gerais de direito, como vem sendo proposto no projeto de lei em discussão.

Além disso, a lei brasileira de direitos autorais é tida pelos especialistas no assunto como uma das mais restritivas do mundo. Percebe-se esse fato, por exemplo, pelo fato da atual LDA proibir a cópia integral de obra alheia, que consequentemente faz com que condutas que se afiguram corriqueiras no mundo contemporâneo, especialmente, a partir da utilização da internet e demais tecnologias, são, a rigor, contrárias à lei. ${ }^{12}$

Por exemplo, a partir de uma interpretação estrita da LDA, quando uma alguém compra um CD em um loja, não pode copiar o conteúdo do CD para seu próprio iPod, o que representa proibição desconexa com o mundo em que vivemos e com as facilidades da tecnologia digital.

Percebe-se, portanto, que todo o sistema de proteção dos direitos autorais se baseia ainda na tutela do autor e na não utilização de sua obra, exceto mediante expressa autorização legal ou com seu consentimento. Para sustentar esta posição, tem-se como principal fundamento a importância de munir o autor mecanismos de proteção à suas criações, de modo a permitir que seja o autor devidamente remunerado e possa, com isso, seguir estimulado para continuar produzindo intelectualmente. ${ }^{13}$

Com isso, sobretudo considerando o avanço tecnológico, representado principalmente pelo advento da Internet, e o grande valor que a informação e a cultura passam a agregar para o desenvolvimento da sociedade como um todo, surge no cenário contemporâneo a necessidade de uma reavaliação acerca do direito de autor, especialmente no que tange as suas limitações e exceções, pois atualmente elas mostram-se insuficientes para que estabeleça o tão buscado equilíbrio de direitos, sob a ótica da função social do direito de autor.

Isto é, se as limitações se mostravam insuficientes no padrão antigo de suportes materiais das obras, quem dirá agora, com a as inúmeras possibilidades digitais, considerando ainda as previsões de alguns especialistas de que num futuro próximo não se terá mais livros, CDs ou DVDs, estando tudo disponibilizado na rede virtual.

Portanto, sob o prisma dos usuários da internet e das novas tecnologias, com a lei 9.610 de 1998 da forma que está, há uma supressão da maioria de seus direitos enquanto usuários de obras intelectuais. Assim, reitera-se que se um consumidor adquire um CD em uma loja e copia aquele mesmo CD ou apenas uma música para o seu MP3 Player, ou ainda se usuário da internet realiza o download de uma música ou de um filme para o seu computador, ele estará transgredindo a lei de direitos autorais, tendo em vista que a lei não permite a cópia integral das obras intelectuais, permitindo tão somente a cópia de pequenos trechos para uso privado do copista. Há uma contradição muito clara e muito forte entre o texto da lei e realidade das práticas tecnológicas assumidas atualmente. 
A partir disso, pode-se afirmar que a Lei 9.610/98 e notadamente as limitações ao Direito de Autor são incompatíveis com os desenvolvimentos tecnológicos atuais e consequentemente com a função social do direito de autor, pois acabam por servir de empecilho à difusão da informação e da cultura. Pode-se, inclusive dizer que por meio de uma interpretação literal do regime atual de direitos autorais, qualquer usuário de internet pode ser transformado em um potencial infrator de direitos ou ainda, de maneira mais drástica, em um potencial criminoso.

\section{UTILIZAÇÃO FORA DAS LIMITAÇÕES: PIRATARIA OU FUNÇÃO SOCIAL?}

Como já referido, as práticas sociais contemporâneas, sob a perspectiva da utilização das obras intelectuais, encontram-se em inúmeras situações em contraposição ao disposto na atual LDA, ou seja, a sociedade, mediante o uso das novas tecnologias, sobretudo a Internet, vem diariamente usufruindo dos bens tutelados pelo direito autoral fora do campo permitido pelas limitações dispostas no artigo 46 da Lei 9.610/98.

Diante dessa situação de contraposição entre a lei e a realidade social cumpre verificar se a utilização dos bens intelectuais da forma que vem ocorrendo, ou seja, além das formas permitidas pela LDA, configura pirataria ou encontra-se dentro da denominada função social do direito de autor, fazendo-se necessário, para tanto, uma breve análise de ambos os termos.

\subsection{Pirataria}

O termo "pirataria", atualmente, tem sido utilizado indistintamente, especialmente pelo chamando setor da indústria de direitos autorais, ou seja, tem-se caracterizado com pirataria, no âmbito do direito de autor, uma miríade de atividades tão distintas quanto a clonagem industrial, em larga escala, para comércio não autorizado de produtos protegidos pelo direito de autor ou a simples cópia doméstica, desses mesmos produtos, para uso particular. ${ }^{14}$

Nesse sentido, tem-se divulgado que qualquer tipo de cópia de obra intelectual sem expressa autorização do titular seja considerada como uma violação penal aos direitos autorais, sendo que, inclusive, muitas vezes a indústria efetua reais ameaças aos supostos "piratas", fundamentando-se, invariavelmente, no artigo 184 e seguintes do Código Penal Brasileiro, que tratam da violação dos direitos de autor e os que the são conexos.

É comum vermos, em filmes, livros, CDs, DVDs, etc, assertivas do tipo "é proibida a reprodução parcial ou integral desta obra", "este material não pode ser publicado, transmitido, reescrito ou redistribuído", "pirataria é crime", "denuncie a falsificação". É proibido ainda "editar", "adicionar", "reduzir", "exibir ou difundir publicamente", "emitir ou transmitir por radiodifusão, internet, televisão a cabo, ou qualquer outro meio de comunicação já existente, ou que 
venha a ser criado", bem como, "trocar", "emprestar" etc., sempre "conforme o artigo 184 do Código Penal Brasileiro". ${ }^{15}$

Com efeito, em primeiro lugar, nesses avisos intimidadores vende-se a idéia de que nem mesmo a cópia de pequenos trechos para uso privado é possível, o que, no entanto a LDA permite no seu art. 46, II. Ainda, a partir desse entendimento tem-se tentado distorcer a própria redação da lei penal, haja vista, que o art. 184 do CP trata como crime somente reprodução, cópia e utilização indevida, que tiver intuito de lucro.

Nesse sentido a própria redação do $\S 4^{\circ}$ do art. 184 do CP é esclarecedor, pois prevê claramente que "O disposto nos $\S \S 1^{\circ}, 2^{\circ}$ e $3^{\circ}$ não se aplica quando se tratar de exceção ou limitação ao direito de autor ou os que the são conexos, em conformidade com o previsto na Lei $\mathrm{n}^{\circ}$ 9.610, de 19 de fevereiro de 1998, nem a cópia de obra intelectual ou fonograma, em um só exemplar, para uso privado do copista, sem intuito de lucro direto ou indireto".

Assim, não pode ser pautado como "pirata" quem simplesmente faz o download de uma música para seu IPOD, copia um CD ou um filme para uso particular e sem fins lucrativos, muito menos com criminoso.

Disso conclui-se que, o termo pirataria da forma indistinta como vem sendo utilizado é efetivamente inapropriado, especialmente quando se trata de reprodução de uma obra pra uso privado, e mais especialmente ainda quando esta reprodução ocorrer para fins culturais ou educacionais, pois nesse caso, mesmo que teoricamente ocorrendo uma violação ao direito de autor, se estará dentro do âmbito do que se denomina de função social do direito de autor, conforme se verá no próximo tópico.

\subsection{Função social}

O direito contemporâneo perpassa por uma nova tendência sob um contexto sócio-jurídico voltada ao atendimento das questões sociais no âmbito das relações privadas. Em razão disso, a funcionalização torna-se regra de aplicação e legitimação dos institutos privados no contexto social, na medida em que procura respaldar conceitos cernes da dignidade da pessoa humana.

Nesta perspectiva o estudo da função social nos institutos de direito privado mostra-se concernente ao direcionamento que vem sendo implementado gradativamente na sociedade, através de uma mudança de paradigmas, do individualismo para a socialização, tendo por escopo a conscientização no que tange ao direcionamento dos institutos privados a uma visão mais social e fraterna nas relações interprivadas.

Assim, seguindo as diretrizes de implementação da denominada constitucionalização do direito privado, através, muito especialmente, da vinculação dos direitos fundamentais às relações privadas, pode-se buscar a delimitação teórica e aplicativa da chamada função social no estudo do direito do autor. 
Sabe-se que o direito de autor, embora caracterize-se como um direito historicamente privatístico, no que tange à proteção do produto de criação da intelectualidade humana, sob essa perspectiva gera interesses individuais e interesses coletivos.

Neste sentido, a fundamentação de tais interesses encontra-se na Carta Constitucional de 1988, quando estabelece de forma expressa, como direitos fundamentais, a proteção autoral no disposto no artigo $5^{\circ}$, incisos XXVII e XXVIII, assim como determina igualmente, o texto constitucional, também, como direito fundamental, a função social da propriedade, art. $5^{\circ}$, inciso XXIII, como paradigma dos institutos privados.

Da mesma forma, mas em contraposição, há a previsão constitucional dos direitos de acesso à informação, à cultura e à educação, previstos nos artigos 5o, inciso XIV, 215, e 205 da Constituição Federal:

Art $5^{\circ}$ [...] XIV - é assegurado a todos o acesso à informação e resguardado o sigilo da fonte, quando necessário ao exercício profissional.

Art. 215. O Estado garantirá a todos o pleno exercício dos direitos culturais e acesso às fontes da cultura nacional, e apoiará e incentivará a valorização e a difusão das manifestações culturais"

Art. 205. A educação, direito de todos e dever do Estado e da família, será promovida e incentivada com a colaboração da sociedade, visando ao pleno desenvolvimento da pessoa, seu preparo para o exercício da cidadania e sua qualificação para o trabalho.

Observa-se um possível conflito de direitos fundamentais visualizados na divergência de interesses individuais do autor com interesses coletivos da sociedade, mais especialmente um conflito do direito à propriedade e à personalidade do autor versus o direito à informação, cultura e educação da sociedade.

Sendo assim, o direito de autor mostra-se num primeiro momento em uma perspectiva voltada a um viés individualista em que se destaca o direito patrimonial e moral do autor, respectivamente na exploração econômica da obra e na proteção da personalidade de autor.

Em outro momento, entretanto, o direito do autor alcança sua finalidade maior, quando da destinação pública da obra, permitindo o acesso da coletividade à cultura, à educação, ao conhecimento e à informação, exsurgindo-se, assim, como patrimônio nacional a ser protegido, pois seus efeitos determinam transformações no complexo intelectual da sociedade.

O Legislador ordinário, ao criar a Lei de Proteção do direito de autor, atualmente a Lei 9610/98, já esteve atento aos interesses da coletividade, ainda que de forma tímida, ao estabelecer no artigo 46 algumas limitações ao seu princípio monopolista. 
Ocorre que, mesmo estando claro que tais limitações mostram-se inadequadas com a realidade social e tecnológica contemporânea, bem como apesar da importância dos interesses educacionais e culturais da sociedade na delimitação dos aspectos privatistas da proteção do autor, boa parte da doutrina especializada, aponta ainda para uma interpretação mais restritiva destes limites, uma vez que os entendem como exceções à regra geral da proteção autoral.

O que se vê, portanto, com relação ao direito autoral, tanto na legislação como na doutrina, com esparsa parcela dissonante na jurisprudência, é um processo inverso, na contra-mão da despatrimonialização e da repersonalização que tem ocorrido no direito civil, muito especialmente, a partir da secunda metade do século passado, pelo crescente processo de sua constitucionalização, em especial, da vinculação dos direitos fundamentais nas ditas relações horizontais entre particulares, onde o princípio da dignidade humana é fixado como princípio matriz de todo o ordenamento e uma das finalidades essenciais do Estado.

O movimento de proteção privatístico e individualista do direito de autor, vem ocorrendo, especialmente, nas últimas três décadas, tanto a nível nacional como internacional, numa ampliação do processo de privatização de seus usos, com uma maior restrição dos usos livres legalmente autorizados, expressando-se, sem dúvida alguma, em tendências patrimonialista e antisocial, caracterizando uma evolução economicista, que sufoca as preocupações com os direitos fundamentais à informação, cultura e educação.

Importante que se lembre que a justificação histórica, repetida até os dias atuais, para a maior proteção do direito individualista do autor, é de cunho econômico-social, ou seja, que toda a tutela do autor reverte em estímulo da criação intelectual. Quanto mais forte fosse essa tutela maior seria o impulso dado à cultura.

Todavia, atualmente, este argumento não é de todo verdadeiro, uma vez que boa parte dos titulares dos direitos patrimoniais das obras protegidas são os intermediários, a quem os autores transmitem ou oneram os seus direitos, ou seja, transferiu-se a proteção do autor-criador para a figura do intermediárioempresário.

Não se trata, portanto, de centrar o problema em uma suposta miséria dos titulares originais, mas sim na relação investimento e lucro que o intermediárioempresário deve obter.

De igual maneira não se está a fazer apologia contrária ao lucro do empresário do setor, mas sim de verificar qual a dosagem de proteção que permita a justa compensação da atividade empresarial do setor e, ao mesmo tempo, permita uma maior facilidade de acesso da coletividade à obra.

O que se busca, portanto, com a defesa da efetivação da função social do direito de autor é, principalmente, uma ampliação das possibilidades de 
utilização social dos bens intelectuais. Isto em razão de direitos fundamentais a serem tutelados, muito especialmente, os já referidos direito à informação, à cultura e à educação.

Frente a isso, considerando que a atual LDA encontra-se incompatível com a realidade tecnológica contemporânea e, consequentemente, com as práticas adotadas pela Sociedade da informação, é necessário que se faça uma leitura extensiva das limitações do Direito de Autor dispostas no artigo 46 da Lei 9.610/98 à luz da Constituição e de todos os direitos fundamentais em jogo, a fim de se buscar a efetivação da função social do direito de autor.

Dessa forma, deve-se entender que a sociedade quando faz uso dos bens intelectuais, para uso próprio, ou mesmo para uso coletivo com fins educacionais ou culturais e sem fins lucrativos, estará dentro do âmbito do que se entende por função social do direito do autor, não podendo taxar-se, de modo algum, tais utilizações das obras como pirataria.

Portanto, o que se quer dizer é que a LDA não pode servir de obstáculo para o acesso da sociedade às obras intelectuais, sobretudo quando este acesso estiver pautado em interesses de cunho social, que em determinadas situações específicas acabam por superar o interesse individual do autor. Nesses casos a utilização do bem imaterial, mesmo que ultrapassando o campo das limitações do artigo 46, não deve ser considerado ilícito, pois recebe respaldo constitucional abarcando a esfera da função social do direito de autor.

\begin{abstract}
A lei não pode impedir o progresso. E nem esta é a sua finalidade. A ciência e o processo de aquisição do conhecimento batalham contra o preconceito, o costume, o tabu, a religião e, também, contra aquilo que, mesmo transformando em lei, impõe restrições à pesquisa científica. $^{16}$
\end{abstract}

Portanto, a internet e outras tecnologias devem poder ser utilizadas tanto a favor da sociedade, no que tange as maiores possibilidade de acesso e compartilhamento das obras intelectuais, quanto do próprio autor, já que por um lado poderá deixar de receber certo valor decorrente da venda em suporte material de sua obra, mas por outro lado terá uma divulgação muito maior da sua obra, do que teria sem o uso da Internet, por exemplo.

Por consequência, para o autor a maior divulgação pode acarretar outras formas de retribuição financeira, como shows, palestras, exposições, etc. Tratase de uma forma de adaptação às novas tecnologias e às novas práticas sociais, isto é, deve a lei adaptar-se à Sociedade da Informação e não a sociedade adaptar-se a atual LDA.

É importante que fique claro que não se pretende acabar com o Direito Autoral ou desproteger o autor, mas tão somente tentar harmonizar uma situação de conflituosidade, para que se permita à sociedade que se beneficie dos meios tecnológicos existentes para o acesso à informação, sem com isso 
deixar de dar a devida proteção ao autor, inclusive como meio de incentivo a contínua criação intelectual.

\section{CONCLUSÃO}

O direito de autor, assim como os demais institutos de direito, nasce, atualmente, umbilicalmente ligado à sua função social, não mais atribuindo, ao seu titular, direito absoluto.

Há necessidade, portanto, de compor de forma eqüitativa os interesses públicos e privados aparentemente colidentes. Aparentemente colidentes, porque na realidade os interesses são comuns porque há o interesse privado do autor em publicar e ver sua obra sendo conhecida e adquirida por todos e, ao mesmo tempo, há o interesse público de maior acesso à obra.

Há, também a necessidade de constante mutação e adequação do direito à efetiva realidade. Todavia, não é o que vislumbra-se atualmente, haja vista o total descompasso existente entre as presentes praticas sociais de utilização das obras intelectuais possibilitadas pelas novas tecnologias e a atual LDA.

Nessa perspectiva, o que não pode ocorrer é a caracterização de qualquer utilização de bens intelectuais que esteja fora da abrangência das limitações dispostas no artigo 46 da LDA como Pirataria, e, portanto, como crime.

Em verdade, com base dos direitos de acesso à informação, a educação e cultura, se a utilização de um bem intelectual tiver fins educacionais ou culturais, sem intuito de lucro, é possível afirmar que nem mesmo um ilícito cível se estará cometendo, pois nesses casos impõe-se uma releitura da LDA sob a ótica constitucional e, que consequentemente, levará a inserir estas formas de utilização como pertencente ao âmbito do que se entende por função social do direito de autor.

\section{USE OF INTELLECTUAL COPYRIGHT WORKS AHEAD TO NEW TECHNOLOGY: SOCIAL FUNCTION OR PIRACY?}

\section{ABSTRACT}

Nowadays there is the existence of a new model of society called the Information Society, that comes, mainly, from the emergence of new communication technologies that facilitate access to information and also to the intellectual works. In this new context, it increases even more the historic conflict between the society and author, specifically as regards the right of access to information of the society and the author's right of remuneration for the use of intellectual assets fruits of his creation. From te discussion of this conflict, especially considering the restrictive nature of the Law 9.610/98 and 
the limitations of right of author, it is possible to see that the current right of author law becomes incompatible with the current social practices made possible by new technologies, much especially by Internet, serving as a barrier to enforcement of fundamental rights to information, education and culture. Thus, the society as a whole has been routinely violating the right of author, so for example when someone download a movie to the computer for private use, or when someone copying music to an iPod even though a CD purchased, or when someone take a copy of a book for educational use, even if the book is exhausted in the libraries, among many other examples. However, this type of use indicated above, that is for private and nonprofit use, can not be called as Piracy and much less treated as a crime, because the right of author, like other private institutions must to have a social function. Therefore, it can be argued that these forms of use of intellectual assets, without intention of profit, are precisely within the scope of what it means for social function of right of author, receiving the incidence, in these cases, from the fundamental rights to information, culture and education.

Keywords: New technologies. Piracy Right of author. Social Function.

\section{NOTAS}

1 Mestrando em Direito pela Universidade de Santa Cruz do Sul - UNISC, Bolsista CAPES PROSUP,Membro do Grupo de Pesquisa: Direito de Autor no Constitucionalismo Contemporâneo. Advogado. E-mail: eduardo.pires12@gmail.com. Endereço: Pires e Frantz Advogados, Rua Marechal Floriano, 286, salas 01,02 e 03 - Centro - CEP 96810-000 Santa Cruz do Sul, RS - Brasil.

2 Pós-Doutor pela Università Degli Studi di Salerno- Itália, Doutor em Direito pela Universidade do Vale do Rio dos Sinos - UNISINOS, Pesquisador e Coordenador do Programa de Pós-Graduação em Direito - Mestrado e Doutorado da UNISC, Coordenador do Projeto de Pesquisa O Direito de Autor no Constitucionalismo Contemporâneo, Professor na graduação da UNISC. Professor colaborador da Scuola di Dottorato in Diritto Tulio Ascarelli da Università Degli Studi di Roma TRE. Professor de cursos de PósGraduação Lato-Sensu da UNIVALI de Biguaçú - SC, da CESUSC de Florianópolis, da UCS de Caxias do Sul - RS, da UNISC, entre outras. Advogado. E-mail: jreis@unisc.br. Endereço: Universidade de Santa Cruz do Sul, Curso de Direito, Mestrado em Direito. Avenida Independência, 2293 - Universitário - CEP 96815-900 - Santa Cruz do Sul, Brasil - Caixa Postal 188.

3 RODRIGUES, Maria de Lurdes. Análise das condições sociais do desenvolvimento da sociedade da informação. Disponível em: $<$ http://www.ricyt.org/interior/normalizacion/VItaller/S4Soc/rodriguesdoc.pdf>. Acesso em: 08 mai. 2009.

4 ADOLFO, Luiz Gonzaga Silva. Obras privadas, benefícios coletivos: a dimensão pública do direito autoral na sociedade da informação. Porto Alegre: Sergio Antonio Fabris Ed., 2008, p. 245.

5 WACHOWICZ, Marcos. Direito fundamental do autor: tensão constitucional entre a propriedade intelectual e o direito à liberdade de informação dos bens informáticos. Anais do V Seminário Internacional de Demandas Sociais e Políticas Públicas na Sociedade Contemporânea. Santa Cruz do Sul: Unisc, 2008.

6 ADOLFO, Luiz Gonzaga Silva. Obras privadas, benefícios coletivos: a dimensão pública do direito autoral na sociedade da informação. Porto Alegre: Sergio Antonio Fabris Ed., 2008, p. 227.

7 GUERREIROS JUNIOR, Nehemias. O direito autoral no show bussiness: tudo o que você precisa saber. 3. ed. Rio de Janeiro: Gryphus, 2005, p 47. 
8 Constituição Federal de 1998, artigo 5ํ, XVII - aos autores pertence o direito exclusivo de utilização, publicação ou reprodução de suas obras, transmissível aos herdeiros pelo tempo que a lei fixar.

9 CONSTITUIÇÃO FEDERAL, artigo 5ำ XVIII, b - São assegurados, nos termos da lei: b) o direito de fiscalização do aproveitamento econômico das obras que criarem ou de que participarem aos criadores, aos intérpretes e às respectivas representações sindicais e associativas.

10 BITTAR, Carlos Alberto. Direito de Autor. 3. ed. Rio de Janeiro: Forense Universitária, 2001. p.10.

11 HAMMES, Bruno Jorge. O direito de propriedade intelectual: subsídios para o ensino. São Leopoldo: Editora Unisinos, 1998. p. 76/77.

12 LEMOS, Ronaldo; BRANCO JUNIOR, Sérgio Vieira. Copyleft, Software Livre e Creative Commons: A Nova Feição dos Direitos Autorais e as Obras Colaborativas. Disponível em: <http://virtualbib.fgv.br/dspace/handle/10438/2796?show=full> Acesso em: 22 ago 2010.

13 Ibidem.

14 ALMEIDA, Manoel. Crimes e excessos no combate à "Pirataria". Disponível em: <http://www.r2learning.com.br/_site/artigos/curso_oab_concurso_artigo_676_Crimes_e_exc essos_no_combate_a_Pirataria>. Acesso em: 25 ago 2010.

15 Ibidem.

16 CABRAL, Plínio. Revolução Tecnológica e o Direito Autoral. 1. ed. Porto Alegre: Sagra Luzzatto, 1998, p. 67.

\section{REFERÊNCIAS}

ADOLFO, Luiz Gonzaga Silva. Obras privadas, benefícios coletivos: a dimensão pública do direito autoral na sociedade da informação. Porto Alegre: Sergio Antonio Fabris Ed., 2008.

BITTAR, Carlos Alberto. Direito de Autor. 3. ed. Rio de Janeiro: Forense Universitária, 2001.

CABRAL, Plínio. Revolução Tecnológica e o Direito Autoral. Porto Alegre: Sagra Luzzatto, 1998.

HAMMES, Bruno Jorge. O direito de propriedade intelectual: subsídios para o ensino. São Leopoldo: Editora Unisinos, 1998.

GUERREIROS JUNIOR, Nehemias. O direito autoral no show bussiness: tudo o que você precisa saber. 3. ed. Rio de Janeiro: Gryphus, 2005.

MORAES, Rodrigo. A função social da propriedade intelectual na era das novas tecnologias. In: BRASIL, Ministério da Cultura. Direito autoral. Brasília: Ministério da Cultura, 2006.

RODRIGUES, Maria de Lurdes. Análise das condições sociais do desenvolvimento da sociedade da informação. Disponível em: <http://www.ricyt.org/interior/normalizacion/ VItaller/S4_Soc/rodriguesdoc.pdf>. Acesso em: 08 mai. 2009.

REIS, Jorge Renato dos. Os fundamentos teórico-constitutivos do direito de autor e a eficácia dos seus contratos no ordenamento jurídico brasileiro. Tese 
de doutorado (Programa de Pós-Graduação em Direito - Mestrado e Doutorado) - Universidade do Vale do Rio dos Sinos, São Leopoldo, 2003.

VITALIS, Aline. A função social dos direitos autorais: uma perspectiva constitucional e os novos desafios da sociedade de informação. In: BRASIL, Ministério da Cultura. Direito autoral. Brasília: Ministério da Cultura, 2006.

WACHOWICZ, Marcos. Direito fundamental do autor: tensão constitucional entre a propriedade intelectual e o direito à liberdade de informação dos bens informáticos. Anais do V Seminário Internacional de Demandas Sociais e Políticas Públicas na Sociedade Contemporânea. Santa Cruz do Sul: Unisc, 2008.

Recebido para publicação: 12/12/2010

Aceito para publicação: 17/12/2010 